\title{
O ENSINO DA MICROBIOLOGIA POR MEIO DE UMA ATIVIDADE EXPERIMENTAL DE LACTOBACILOS
}

\author{
THE TEACHING OF MICROBIOLOGY THROUGH AN EXPERIMENTAL ACTIVITY \\ OF LACTOBACILLI
}

\begin{abstract}
Matheus Felipe dos Reis Rodrigues ${ }^{1}$, Leonardo de Paula Pereira², Márcio Pedro de Andrade $^{3}$, Marisa Cristina da Fonseca Casteluber ${ }^{4}$, Fernanda de Jesus Costa ${ }^{5}$

1 Universidade do Estado de Minas Gerais, Departamento de Ciências Biológicas, Brasil, E-mail: matheusfelipe2552@gmail.com, ORCID: https://orcid.org/0000-0002-4469-2534

2 Universidade do Estado de Minas Gerais, Departamento de Ciências Biológicas, Brasil, E-mail: leonardopp127@gmail.com, ORCID: https://orcid.org/0000-0002-2149-7154

3 Universidade do Estado de Minas Gerais, Departamento de Ciências Biológicas, Brasil, E-mail: pedromarcioandrade59@gmail.com, ORCID: https://orcid.org/0000-0003-1938-3067

4 Universidade do Estado de Minas Gerais, Departamento de Ciências Biológicas, Brasil, E-mail: marisa.casteluber@uemg.br, ORCID: https://orcid.org/0000-0002-4156-641X

5 Universidade do Estado de Minas Gerais, Departamento de Ciências Biológicas, Brasil, E-mail: fernanda.costa@uemg.br, ORCID: https://orcid.org/0000-0002-1517-8931
\end{abstract}

ARTICLE INFO

Article history:

Received 2020-09-19

Accepted 2020-12-12

Available online 2020-12-12
Palavras-chave: Microbiologia. Atividade experimental. Bactérias. Lactobacilos.

Keywords: Microbiology. Experimental activity. Bacteria. Lactobacilli.

RESUMO. A Microbiologia é um ramo das Ciências Biológicas que se dedica ao estudo dos seres microscópicos, a relação desses com outros seres e com o meio no qual estão inseridos. Essa é uma disciplina de grande relevância dentro e fora do ambiente escolar, mas abordar conceitos dessa área no ensino de Ciências nas escolas é um grande desafio devido a sua abstração e limitação de materiais e recursos. Nesse contexto, o presente trabalho teve por objetivo analisar as contribuições de uma atividade experimental sobre as bactérias como facilitadora para o aprendizado dos estudantes de quatro turmas do $7^{\circ}$ ano do Ensino Fundamental de uma escola pública no Município de Ibirité, em Minas Gerais. Os dados obtidos foram provenientes da observação dos pesquisadores envolvidos e de um questionário estruturado preenchido pelos estudantes após a realização da atividade. Os resultados permitem inferir que a atividade experimental contribui para o processo de ensino-aprendizagem sobre os microrganismos, em especial as bactérias. Além disso, permitem sugerir que atividades experimentais sejam utilizadas de forma mais assídua no ensino de Ciências.

ABSTRACT. Microbiology is a branch of science that is dedicated to the study of microscopic beings and their relationship with other beings and also with the environment in which they are inserted. This is a subject of great relevance inside and outside the school environment, but addressing concepts in this area in science teaching in schools is a great challenge due to its abstraction and lack of materials and resources. In this context, the present work aimed to analyze the contributions of an experimental activity on bacteria to make it easy for students learning from four classes of the 7th year of elementary school at a public school in the Municipality of Ibirité, in Minas Gerais. The data obtained came from the observation of the researches involved and from a report completed by the students after the activity was carried out. The results obtained allow us to infer that the experimental activity contributes to the teaching and learning processes about microorganisms, especially bacteria. Thus, it is suggested that experimental activities be used more assiduously in science teaching. 


\section{Introdução}

A Microbiologia dedica-se ao estudo dos microrganismos, bem como as suas diversidades morfológicas, fisiológicas, e as interações que esses seres possuem com o meio ambiente e com outros seres vivos (PELCZAR, et al., 1997). Os organismos microscópicos que são alvo dessa Ciência são as bactérias, os vírus, os fungos, os protozoários, alguns parasitas e as algas unicelulares.

Muitos microrganismos são utilizados amplamente em diversos setores da indústria para a produção de insumos, como fármacos (antibióticos, anticorpos monoclonais e vacinas) (REIS, et al., 2009) ou alimentos (laticínios, fermentação em pães e bebidas fermentadas ou alcoólicas). Há também a utilização desses seres no combate e controle de pragas agrícolas que beneficiam produtores rurais com a diminuição da perda de frutos e vegetais.

Outros seres microscópicos possuem destaque por comporem a microbiota de alguns seres vivos trazendo benefícios, como é o caso do ser humano que possui diversas bactérias no intestino que ajudam na absorção de nutrientes. Recentemente tem sido mostrado a importância dos microrganismos que compõem o microbioma intestinal para o Sistema Imunológico, uma vez que atuam como probióticos capazes de proteger o organismo de várias infecções e doenças (BARRETO, 2018).

No meio ambiente os microrganismos exercem uma grande importância na manutenção e integridade dos ecossistemas. Muitos realizam a fixação de nutrientes como o nitrogênio, fósforo e enxofre no solo para a renovação dos ciclos biogeoquímicos, já outros classificados como decompositores ou saprófitos transformam a matéria orgânica em inorgânica permitindo o desenvolvimento de novos organismos vegetais.

Todos esses destaques e aplicabilidades confirmam que os microrganismos são ubíquos e exercem incontáveis influências em nossa sociedade e nos nossos hábitos de vida (MORESCO, et al., 2017). Nesse cenário o ensino da Microbiologia possui grande relevância no ambiente escolar, pois os estudantes adquirem conhecimentos sobre o meio ambiente, o corpo humano, a saúde dos seres vivos, as novas tecnologias desenvolvidas e as relações que os microrganismos possuem.

Segundo os Parâmetros Curriculares Nacionais de Ciências Naturais (PCN) os conceitos microbiológicos estão nos eixos temáticos de "Ambiente", "Ser humano e saúde" e "Recursos tecnológicos" no Ensino Fundamental (BRASIL, 1997). Atualmente com a Base Nacional Comum Curricular (BNCC) os objetos de conhecimento do ensino da Microbiologia no ensino básico são: o "Corpo humano (EF01Cl03)"; "Cadeias alimentares simples e microrganismos (EF04Cl06, EF04CI07, EF04CI08)"; "Materiais sintéticos (EF06Cl04)"; 
"Célula como unidade da vida (EF06Cl05)"; e "Programas e indicadores de saúde pública (EF07Cl10)" (BRASIL, 2017). Esses objetos de conhecimento por estão inseridos nas Unidades Temáticas: "Matéria e energia" e "Vida e evolução".

Apesar dos PNC em Ciências Naturais e a BNCC destacarem a importância dos saberes microbiológicos, o processo de ensino-aprendizagem da Microbiologia não acontece de forma satisfatória. Diversos fatores relacionam-se com esse problema, dos quais podemos citar como exemplo, a utilização excessiva do modelo de "educação tradicional", a falta de contextualização com o cotidiano e o ensino "abstrato" que são os mais recorrentes no ambiente escolar.

Segundo Welker (2007) o modelo de "educação tradicional" contempla metodologias centradas na aquisição passiva do conhecimento pelos estudantes. As aulas são geralmente realizadas de maneira expositiva e teórica, obrigando os discentes a decorarem nomes, estruturas e conceitos que não fazem relações com o cotidiano vivenciado por esses. Nesse cenário os estudantes perdem o interesse pelo conteúdo, e caracterizam a Ciência como uma disciplina desinteressante.

Já o ensino de conceitos "abstratos" (presente muitas vezes na Ciência) é realizado quase que exclusivamente por métodos teóricos ou expositivos. Os estudantes nesse cenário sem acesso a um exemplar didático para tocarem ou visualizarem, sentem-se muitas vezes desmotivados, o que dificulta a aprendizagem em determinados conteúdos. Geralmente os livros didáticos fornecem imagens e fotografias de alta qualidade a partir de microscopias eletrônicas em suas diversas aplicações, mas mesmo com essa disponibilidade a aprendizagem não se faz significativa.

O ensino das bactérias (Reino Monera) pode ser um exemplo dessa problemática apresentada, pois apesar desses seres estarem presentes nos mais variados locais e ainda participarem do cotidiano dos discentes (presentes em laticínios), eles possuem dimensões microscópicas, invisíveis a olho nu, o que dificulta a compreensão da sua importância e aplicação.

A inserção de metodologias alternativas e de atividades experimentais podem ser boas possibilidades para contornar os problemas de um ensino "abstrato" e de uma aprendizagem pouco significativa em Microbiologia. Com a utilização dessas metodologias os estudantes têm a possibilidade de fazerem uma reflexão da teoria ensinada em sala de aula com a experimentação que muitas vezes se assemelha com o seu cotidiano (BARBOSA, BARBOSA, 2010).

A utilização de atividades experimentais possibilitaria o ensino da Microbiologia mais significativo, já que os estudantes poderiam participar ativamente do processo de aquisição de conhecimento e a construção de sua própria aprendizagem. Moresco e colaboradores (2017) destacam que a "vivência" da experimentação pode desenvolver nos estudantes as "habilidades cognitivas de resolver situações problemáticas, predizer respostas, testar 
hipóteses, argumentar, discutir com os pares e podendo atingir a compreensão do conteúdo".

Do mesmo modo, Bizzo (2009) destaca que "a experimentação é um elemento essencial nas aulas de Ciências, mas que essa por si só não garante um bom aprendizado", ou seja, diversas metodologias devem ser utilizadas de maneira articulada para que haja um processo de ensino-aprendizagem satisfatório e significativo. Atividades experimentais, jogos didáticos, júris simulados, trabalhos de campo e outras metodologias se fazem necessárias para o ensino de áreas das Ciências como é o caso da Microbiologia.

Nesse contexto, a utilização de uma atividade experimental logo após uma aula expositiva dialogada para o ensino de conteúdos microbiológicos trará contribuições para o aprendizado dos estudantes. Sendo assim, o objetivo deste estudo ${ }^{1}$ foi verificar a contribuição de uma atividade experimental com estudantes do $7^{0}$ ano do Ensino Fundamental de uma escola pública no Município de lbirité sobre as bactérias.

\section{Procedimentos metodológicos}

O presente trabalho caracteriza-se como quali-quantitativo na medida em que busca compreender os aspectos relacionados com a aplicação de uma atividade experimental para o ensino da Microbiologia. De acordo com Minayo (2008) a pesquisa qualitativa busca compreender um fenômeno por meio de concepções, valores e crenças. Já a pesquisa quantitativa busca entender os fenômenos por meio de dados numéricos, estatísticos ou logarítmicos.

O público alvo foram 124 estudantes de 4 turmas do $7^{\circ}$ ano do Ensino Fundamental de uma escola pública no Município de Ibirité. A experimentação foi realizada no laboratório de Ciências da escola e em cada turma os participantes foram divididos em duplas para às seis bancadas de trabalho o que resultou em 15 duplas na turma A, B e C, e 17 duplas na turma D.

No início da intervenção foi realizado uma revisão de forma expositiva dialogada com o auxílio de um projetor multimídia sobre as bactérias. Essa revisão contemplava a morfologia, fisiologia, reprodução e algumas doenças causadas por bactérias como a tuberculose, cólera, a pneumonia, a leptospirose e a meningite bacteriana. Também foi abordado aspectos sobre os testes com subprodutos para a produção de medicamentos antimicrobianos como aqueles utilizados nos testes de antibiograma.

\footnotetext{
${ }^{1}$ O presente trabalho faz parte de um projeto de pesquisa que objetiva a criação e o desenvolvimento de um Clube de Ciências em uma escola pública no Município de Ibirité. Nesse contexto a utilização de metodologias alternativas, oferecer uma nova perspectiva sobre o ensino de Ciências e o estímulo da Iniciação Científica Júnior são alguns dos objetivos específicos.
} 
Em seguida foi projetada uma lâmina de bactérias coradas pela técnica de Gram e que possuía forma de cocos. A projeção ocorreu por meio do acoplamento de uma câmera à lente ocular do microscópio óptico e que foi transmitida para um projetor multimídia (Figura 1). As etapas da técnica de Gram, bem como as diferenças entre as bactérias Gram positiva e Gram negativa foram explicadas de forma resumida para fundamentar a importância da microscopia em testes laboratoriais.

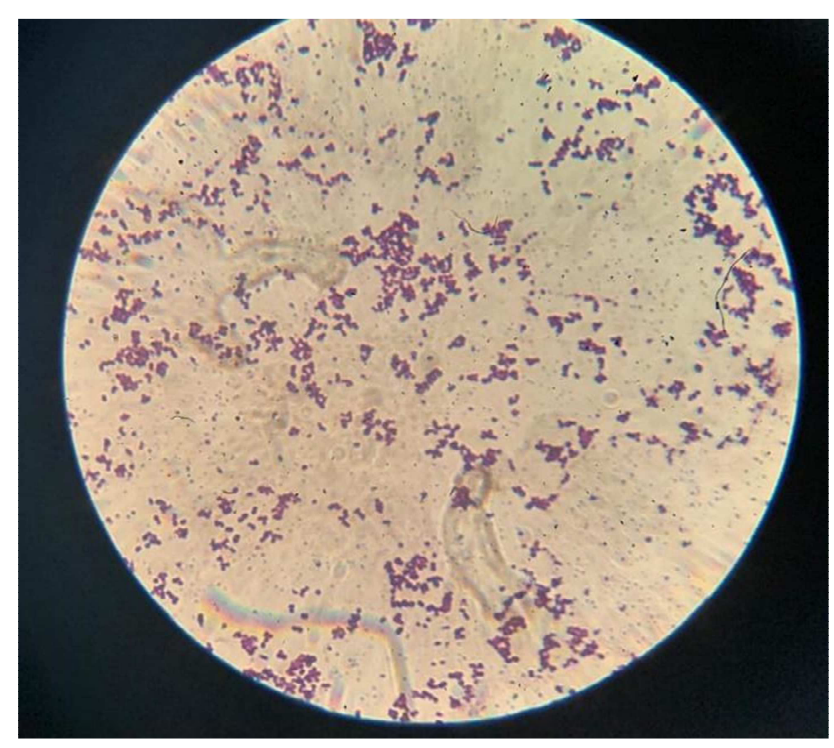

Figura 1- Bactérias no formato de cocos no aumento de 1000x projetadas aos estudantes.

Fonte: Os autores (2020)

Após a explicação cada dupla recebeu um protocolo da atividade que seria realizada, nele havia as orientações e algumas questões referentes ao experimento. Em seguida foi disponibilizado para cada bancada, uma lâmina e uma lamínula de vidro, duas pipetas de Pasteur de plástico, um frasco de leite fermentado e um frasco contendo o corante azul de metileno.

Apesar do último material (azul de metileno) ser utilizado na microscopia para a coloração de estruturas fúngicas, principalmente leveduriformes para a contagem de células viáveis, ele foi utilizado nesta atividade devido à indisponibilidade de material para a coloração pela técnica de Gram. Esse princípio foi destacado com os estudantes com a argumentação de que esse corante era o único recurso presente no laboratório que conferia contraste para a identificação das bactérias do leite fermentado no microscópio óptico.

Em seguida um estudante de cada bancada (escolhido por sorteio ou por escolha dos integrantes da própria bancada) realizou as seguintes etapas da experimentação (figura 2): pipetou uma gota do leite fermentado (etapa 1) e verteu no meio da lâmina de vidro 
(etapa 2), pipetou uma gota de azul de metileno (etapa 3) e verteu sobre o leite fermentado (etapa 4), inseriu a lamínula sobre o corante e levou a lâmina a fresco para ser observada no microscópio óptico (etapa 5 e 6).

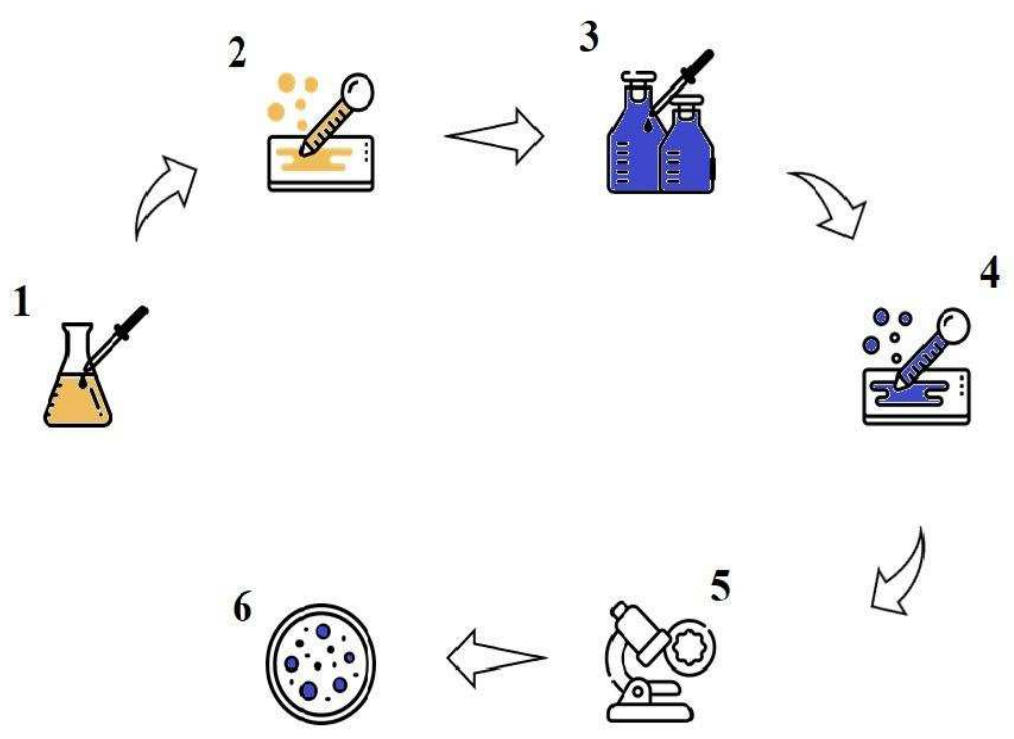

Figura 2 - Esquema ilustrativo das etapas da experimentação.

Fonte: Os autores (2020)

Após a lâmina a fresco ter sido encaixada na mesa do microscópio, os estudantes foram ensinados a manusear o parafuso macro e micrométrico já que cada participante possuía um grau de visão diferente. Após a observação os discentes retornaram às bancadas para preencherem e responderem às questões presentes no relatório da atividade experimental.

Ao todo o protocolo possuía três questões relacionadas com a revisão dada no início da intervenção e com aspectos observados durante a experimentação, como demonstra a tabela 1 abaixo. Destaca-se que as questões foram as mais objetivas possíveis para que toda a intervenção fosse realizada em um período de 50 minutos (hora aula).

Tabela 1 - Questões presentes no relatório da atividade experimental-

\begin{tabular}{|c|l|}
\hline Número da questão & \multicolumn{1}{|c|}{ Descrição da questão } \\
\hline 01 & $\begin{array}{l}\text { Qual a diferença entre as células eucariontes e } \\
\text { procariontes? }\end{array}$ \\
\hline 02 & Quais estruturas compõem as células bacterianas? \\
\hline 03 & Cite no mínimo três doenças causadas por bactérias. \\
\hline
\end{tabular}

Fonte: Os autores (2020). 
Respondida às questões, os protocolos foram entregues para que uma análise qualiquantitativa pudesse ser realizada seguindo os critérios previamente estabelecidos de "Pouco satisfatório (PS)", "Parcialmente satisfatório (ParS)", e "Completamente satisfatório (CS)", como demonstra a tabela 2 abaixo:

Tabela 2 - Critérios da análise das questões

\begin{tabular}{|c|c|c|c|}
\hline $\begin{array}{c}\text { Critérios de } \\
\text { avaliação }\end{array}$ & Questão 1 & Questão 2 & Questão 3 \\
\hline PS & Não citar organelas & Não citar organelas & Não responder \\
\hline ParS & $\begin{array}{c}\text { Citar as organelas, mas } \\
\text { não dizer quais }\end{array}$ & Citar uma organela & Citar uma doença \\
\hline CS & $\begin{array}{c}\text { Citar a membrana } \\
\text { nuclear }\end{array}$ & $\begin{array}{c}\text { Citar o DNA disperso no } \\
\text { citoplasma, membrana } \\
\text { plasmática, ribossomo e } \\
\text { estruturas de locomoção }\end{array}$ & $\begin{array}{c}\text { Citar três ou mais } \\
\text { doenças }\end{array}$ \\
\hline
\end{tabular}

Fonte: Os autores (2020).

\section{Resultados e Discussão}

A atividade experimental desenvolvida com as turmas do $7^{\circ}$ ano do Ensino Fundamental resultou em contribuições no processo de ensino-aprendizagem em Microbiologia. Foi possível observar que os estudantes tiveram grande interesse pela atividade em questão, pois puderam manipular materiais e equipamentos do ambiente laboratorial. Essa é uma característica marcante de um ensino significativo já que os discentes se tornaram ativos em seu processo de aprendizagem.

A utilização das bactérias do leite fermentado (Lactobacillus $s p$ ) foi importante para que os discentes passassem a compreender que os microrganismos estão presentes em seu cotidiano e que somente uma pequena parcela desses trazem malefícios para o ser humano. Dessa forma foi possível constatar que os participantes da atividade tiveram um novo olhar acerca das bactérias trabalhadas anteriormente de forma teórica em uma sala de aula convencional.

Além disso, os estudantes também passaram a associar e refletir sobre os outros benefícios que os microrganismos proporcionam, como: decomposição de resíduos orgânicos, fixação de nutrientes no solo, composição da microbiota intestinal, fabricação de alimentos, desenvolvimento de fármacos, dentre outros. Isso já é um bom resultado para a compreensão da importância que esses seres microscópicos possuem em todos os ambientes e em todas as áreas de nosso cotidiano. 
Outra contribuição proveniente da utilização das bactérias do leite fermentado foi a "concretização" do conteúdo, pois os estudantes puderam visualizar esse microrganismo no microscópio óptico (Figura 3) que muitas vezes só seria visualizado no livro didático. O fato dos próprios discentes terem preparado a lâmina a fresco desde a colocação do microrganismo até a manipulação do microscópio, despertou mesmo que parcialmente o pensamento científico e a busca pela informação para o aprendizado.

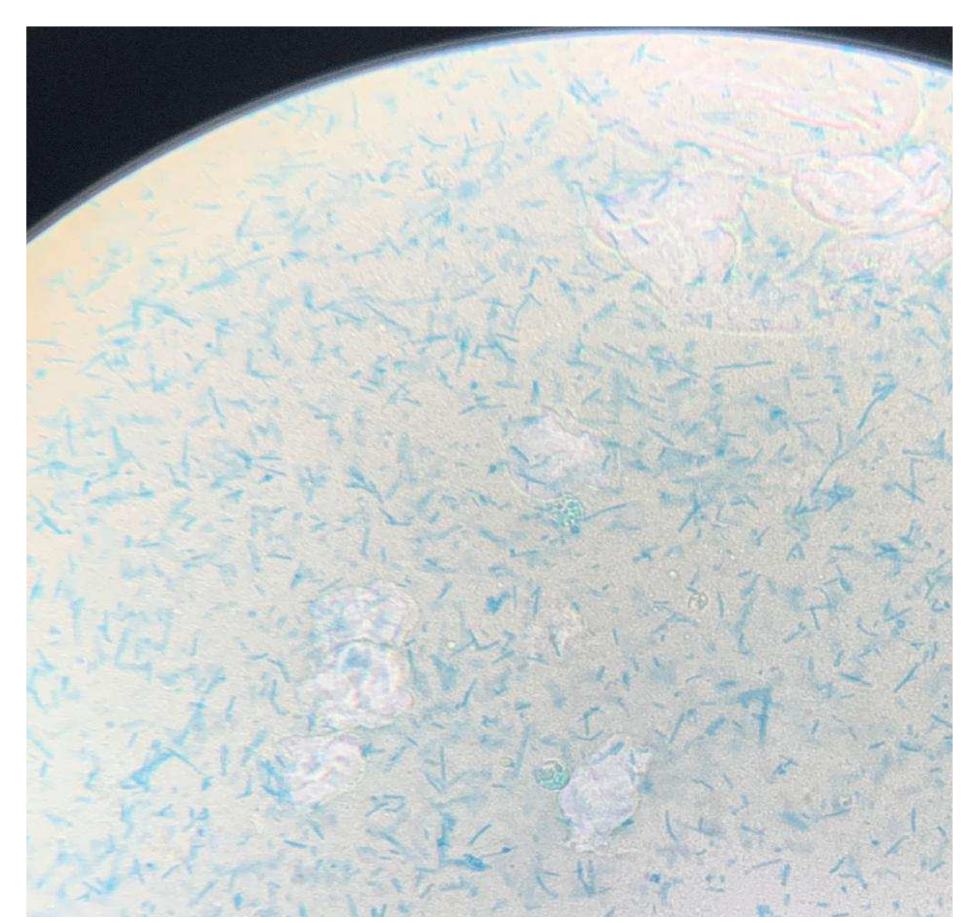

Figura 3 - Bactérias presentes no leite fermentado (Lactobacillus sp) coradas com azul de metileno. (Aumento de 400x).

Fonte: Os autores (2020)

Esses resultados demonstram que as atividades experimentais são elementos essenciais para a consolidação do aprendizado dos estudantes e para o processo de ensino em conceitos da área microbiológica. Porém, como já destacado anteriormente a experimentação sozinha não garante um bom aprendizado (BIZZO, 2009), ela deve atuar em conjunto com outras metodologias para contribuir efetivamente com o processo de ensino-aprendizagem no ambiente escolar.

Já os protocolos que os estudantes preencheram ao final da atividade foram analisados tendo como base a quantificação de acertos para se obter os dados que confirmem se a metodologia contribuiu ou não para o ensino das bactérias. Essa quantificação foi classificada em três categorias como demonstrado na tabela 2. Após a análise dos dados três gráficos foram criados para discutir o desempenho dos estudantes em cada uma das questões. 
Na primeira questão (gráfico 1) 43 duplas de estudantes tiveram um desempenho completamente satisfatório, pois conseguiram identificar a membrana nuclear (carioteca) como a principal estrutura que diferencia as células eucariontes das células procariontes. Já 9 duplas foram parcialmente satisfatórias, pois citaram que haver organelas diferentes entre as duas categorias de células, mas não especificaram quais. As 10 duplas restantes não identificaram diferenças entre os tipos celulares, obtendo um desempenho pouco satisfatório.

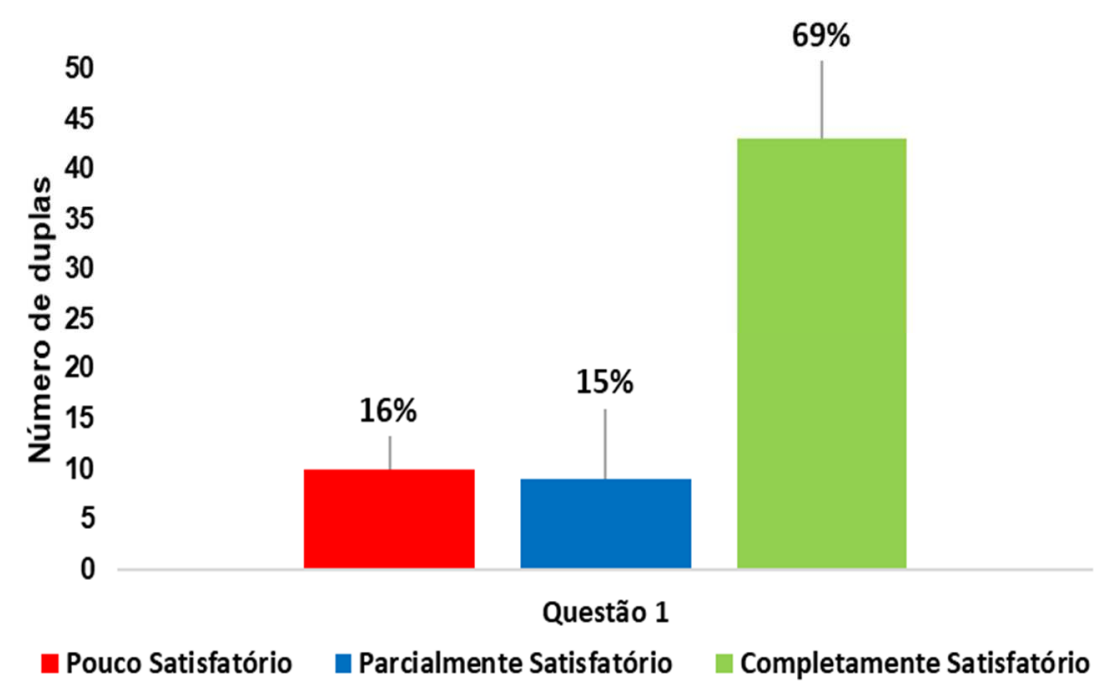

\section{Gráfico 1 - Porcentagem das respostas da questão 1 - “Qual a diferença entre as} células eucariontes e procariontes?"

Fonte: Os autores (2020)

As porcentagens $15 \%$ e $16 \%$ são indicadores de que no corpo discente a dificuldade na compreensão dos dois tipos celulares existentes. Segundo a pesquisa de Moresco e colaboradores (2017) esses dados podem estar relacionados com o fato de muitos estudantes associarem os microrganismos como seres não vivos e nem formados por células, ou seja, esse aspecto precisa ser abordado mais eficientemente no ambiente escolar considerando a importância que esse conteúdo apresenta.

$\mathrm{Na}$ segunda questão (gráfico 2) 32 duplas responderam de forma parcialmente satisfatória, citando no mínimo uma organela ou estrutura que compõe a célula bacteriana. Já 23 duplas obtiveram um desempenho completamente satisfatório, pois citaram o material genético disperso no citoplasma, membrana plasmática, parede celular, ribossomos e alguma estrutura de locomoção (flagelos ou cílios) presentes na célula bacteriana. Com o menor percentual dentre os resultados dessa questão 7 duplas responderam de forma pouco satisfatória, não citando nem organelas, nem o material genético. 


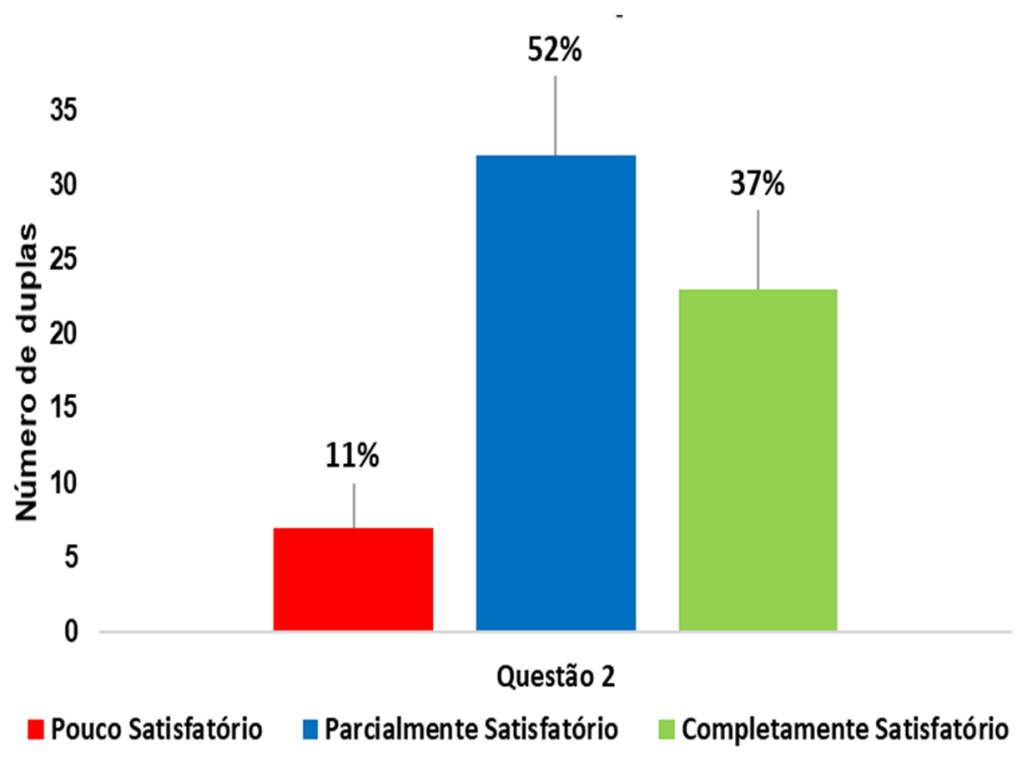

Gráfico 2 - Porcentagem das respostas da questão 2 - "Quais estruturas compõem as células bacterianas?"

Fonte: Os autores (2020)

Com a observação dos dados até agora apresentados foi possível verificar ser preciso abordar mais eficientemente os aspectos relacionados às estruturas presentes da célula bacteriana da questão 2, pois a diferença entre as respostas "completamente satisfatória" e "parcialmente satisfatória" não foram significativas como demonstra a interseção da linha de erro padrão. Isso permite inferir que os estudantes possuem dificuldades nos conteúdos da área citológica que influencia assiduamente em um aprendizado parcial em conceitos microbiológicos (MORESCO, et al., 2017).

Diferente das duas primeiras questões, podemos observar nos dados da terceira questão (gráfico 3) em que é abordado as doenças causadas por bactérias que 53 duplas responderam de forma completamente satisfatória, citando três ou mais doenças causadas pelas bactérias. Seguido de 8 duplas que responderam de forma parcialmente satisfatória, citando ao menos uma doença bacteriana. E por fim 1 dupla ("pouco satisfatório") que não responderam nenhuma doença, ou seja, deixaram a questão em branco. 


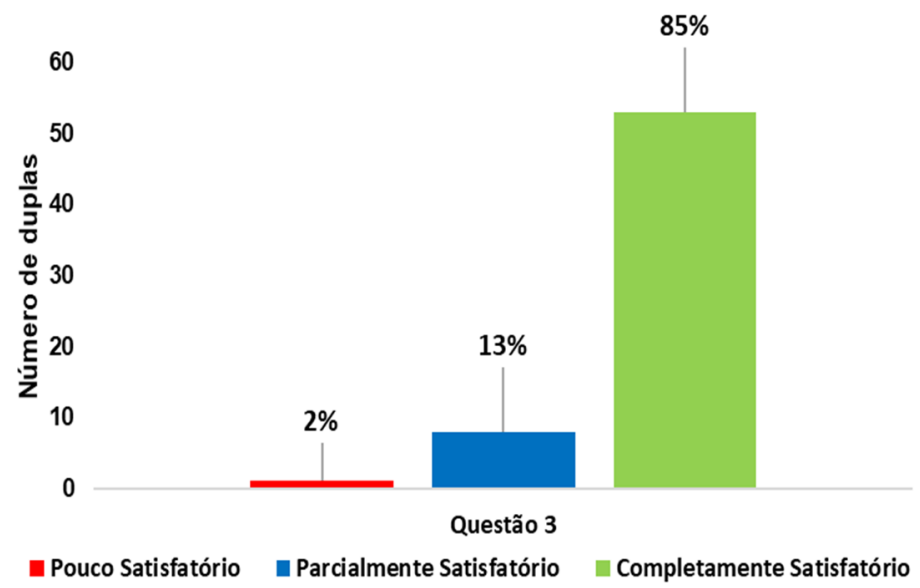

Figura 3 - Porcentagem das respostas da questão 3 - "Cite no mínimo três doenças causadas por bactérias".

Fonte: Os autores (2020)

Além de realizar a análise de acordo com as categorias estabelecidas nessa questão, optou-se por analisar também os exemplos apresentados pelos estudantes. Com base nas respostas analisadas é possível notar que as 5 doenças mais citadas (tuberculose, cólera, leptospirose, meningite e pneumonia) foram as mesmas doenças apresentadas na revisão no início da intervenção, ou seja, os estudantes assimilaram o conteúdo falado. Já as doenças menos citadas (tétano, febre maculosa, lepra, difteria e coqueluche) não foram apresentadas na revisão inicial, o que permite inferir que alguns estudantes já possuem um conhecimento prévio dessas doenças. A tabela 3 apresenta as doenças que foram destacadas pelos estudantes participantes da pesquisa.

Tabela 3 - Doenças citadas pelos estudantes

\begin{tabular}{|l|c|}
\hline \multicolumn{1}{|c|}{ Doenças } & № de duplas \\
\hline Tuberculose & $51(82 \%)$ \\
\hline Cólera & $41(66 \%)$ \\
\hline Leptospirose & $32(52 \%)$ \\
\hline Meningite & $20(32 \%)$ \\
\hline Pneumonia & $13(21 \%)$ \\
\hline Tétano & $8(13 \%)$ \\
\hline Febre Maculosa & $3(5 \%)$ \\
\hline Lepra & $2(3 \%)$ \\
\hline Difteria & $1(2 \%)$ \\
\hline Coqueluche & $1(2 \%)$ \\
\hline N/A - não responderam & $1(2 \%)$ \\
\hline
\end{tabular}

Fonte: Os autores (2020). 
Desse modo, pode ser observado que a presente atividade experimental em Microbiologia trouxe contribuição para a aprendizagem dos estudantes, pois tanto os dados qualitativos quanto os quantitativos demonstram que os mesmos compreenderam aspectos relevantes dessa área no ambiente escolar.

\section{Considerações finais}

O ensino da Microbiologia nas escolas não é tarefa fácil, os estudantes apresentam dificuldades em compreender aspectos básicos dessa disciplina que possui grande abstração. Nesse cenário a utilização da experimentação contribui de forma efetiva para o processo de ensino-aprendizagem dessa Ciência.

Os estudantes do $7^{\circ}$ ano participantes deste estudo foram beneficiados com a utilização de uma atividade experimental sobre as bactérias, o que pôde ser constatado pelas respostas dos protocolos e às questões por eles levantadas durante a participação na atividade. Desta forma, pode ser sugerido que a utilização dessa e de outras experimentações sejam frequentes no ensino da Microbiologia nas escolas.

Apesar das dificuldades existentes para a realização desse método atividades em algumas escolas, o estudo permite sugerir que outras metodologias sejam também utilizadas como: vídeos didáticos, modelos em 3D, saídas de campo, e muitas outras abordagens que diferem da costumeira aula expositiva/teórica da "educação tradicional" de modo a contribuir efetivamente para o processo de ensino-aprendizado em Microbiologia.

\section{Agradecimentos}

O presente trabalho foi realizado com apoio da professora Natália Murta de Lima Dornelas, da Fundação Helena Antipoff - FHA, e pela Universidade do Estado de Minas Gerais - UEMG (Unidade de Ibirité).

\section{REFERÊNCIAS}

BARBOSA, Flávio Henrique Ferreira; BARBOSA, Larissa Paula Jardim de Lima. Alternativas metodológicas em Microbiologia - viabilizando atividades práticas. Revista de Biologia e Ciências da Terra, v. 10, n. 2, 2010.

BARRETO, Bruno Acatauassú Paes. Microbioma and probiotics: from gut to Mars. Brazilian Journal of Otorhinolaryngol., v. 84, n1. 2018.

BIZZO, Nelio. Ciência: fácil ou difícil? 1ª ed. São Paulo: Biruta, 2009. pp. 94-95. 
BRASIL. Secretaria de Educação Fundamental. Parâmetros curriculares nacionais: ciências naturais. Secretaria de Educação Fundamental. Brasília: MEC/SEF, 1997.

BRASIL. Base Nacional Comum Curricular (BNCC): Competências e habilidades de Ciências do Ensino Fundamental. Brasília: MEC: 2017.

MINAYO, Maria Cecília de Souza. O desafio da pesquisa social. In: MINAYO, Maria Cecília de Souza (Org). Pesquisa Social: Teoria, método e criatividade. 27. Ed. Petrópolis, RJ: Vozes, 2008. P. 9-30.

MORESCO, Terimar Ruoso; ROCHA, João Batista Teixeira da; BARBOSA, Nilda Berenice de Vargas. Ensino de Microbiologia e a Experimentação no Ensino Fundamental. Revista Contexto \& Educação, v. 32, n. 103, p. 165-190, 1 dez. 2017.

PELCZAR, M. J. J.; CHAN, E. C. S.; KRIEG, N. R. Microbiologia: conceitos e aplicações. 2. ed. v. 1. São Paulo: Makron Books, 1997.

REIS, Carla; et al. Biotecnologia para saúde humana: Tecnologias, aplicações e inserção na indústria farmacêutica. BNDS Setorial, Rio de Janeiro, n.29, p. 359-392, mar. 2009.

WELKER, Cassiano Aimberê Dorneles. Estudo de Bactérias e Protistas no Ensino Médio: uma abordagem menos convencional. Revista Eletrônica Experiências em Ensino de Ciências, Porto Alegre, v. 2, n. 2, p. 69-75, 2007. 